\title{
Tomographic and functional findings in severe COPD: comparison between the wood smoke-related and smoking-related disease*
}

\author{
Diferencias tomográficas y funcionales entre la EPOC \\ severa relacionada con humo de leña y con cigarrillo
}

\author{
Mauricio González-García, Dario Maldonado Gomez, Carlos A. Torres-Duque, \\ Margarita Barrero, Claudia Jaramillo Villegas, Juan Manuel Pérez, Humberto Varon
}

\begin{abstract}
Objective: Wood smoke exposure is a risk factor for COPD. For a given degree of airway obstruction, the reduction in DLCO is smaller in individuals with wood smoke-related COPD than in those with smoking-related COPD, suggesting that there is less emphysema in the former. The objective of this study was to compare HRCT findings between women with wood smoke-related COPD and women with smoking-related COPD. Methods: Twenty-two women with severe COPD ( $\mathrm{FEV}_{1} / \mathrm{FVC}$ ratio $<70 \%$ and $\mathrm{FEV}<50 \%$ ) were divided into two groups: those with wood smoke-related COPD $(n=12)$ and those with smoking-related COPD $(n=10)$. The two groups were compared regarding emphysema scores and airway involvement (as determined by HRCT); and functional abnormalities-spirometry results, DLCO, alveolar volume (VA), the DLCO/VA ratio, lung volumes, and specific airway resistance (sRaw). Results: There were no significant differences between the two groups in terms of $\mathrm{FEV}_{1}$, sRaw, or lung hyperinflation. Decreases in DLCO and in the DLCO/VA ratio were greater in the smoking-related COPD group subjects, who also had higher emphysema scores, in comparison with the wood smoke-related COPD group subjects. In the wood smoke-related COPD group, HRCT scans showed no significant emphysema, the main findings being peribronchial thickening, bronchial dilation, and subsegmental atelectasis. Conclusions: Female patients with severe wood smoke-related COPD do not appear to develop emphysema, although they do show severe airway involvement. The reduction in DLCO and VA, with a normal DLCO/VA ratio, is probably due to severe bronchial obstruction and incomplete mixing of inspired gas during the determination of single-breath DLCO.
\end{abstract}

Keywords: Pulmonary disease, chronic obstructive; Tomography; Air pollution; Biomass; Smoke; Respiratory function tests.

\section{Resumen}

Objetivo: La exposición a humo de leña es factor de riesgo para EPOC. A diferencia de la EPOC por cigarrillo (EPOC-C), para un mismo nivel de obstrucción, en la EPOC por leña (EPOC-L), la DLCO está menos disminuida, sugiriendo menos enfisema. Por tanto, el objetivo de este estudio fue comparar los hallazgos en la TCAR en mujeres con EPOC-L y con EPOC- C. Métodos: Veintidós mujeres con EPOC severa $\left(\mathrm{VEF}_{1} / \mathrm{CVF}<70 \%\right.$ y $\mathrm{VEF}_{1}<50 \%$ ) fueron divididas en dos grupos: las expuestas a leña (EPOC-L; $n=12$ ) y las expuestas a cigarrillo (EPOC-C; $n=10$ ). Se compararon los dos grupos con respecto al puntaje de enfisema y el compromiso de la vía aérea en la TCAR, las anormalidades funcionales en la espirometría, la DLCO, los volúmenes pulmonares y la resistencia específica de la vía aérea (sRaw). Resultados: Los dos grupos tuvieron $\mathrm{VEF}_{1}$, sRaw e hiperinflación pulmonar similares. En el grupo EPOC-C, hubo mayor disminución de la DLCO y de la DLCO/VA y mayor puntaje de enfisema. En el grupo EPOC-L, no encontramos enfisema significativo en la TCAR. Los hallazgos principales fueron engrosamiento peribronquial, dilataciones bronquiales y atelectasias subsegmentarias. Conclusiones: En pacientes con EPOC-L severa no hay enfisema en la TCAR. El hallazgo más importante es el compromiso severo de la vía aérea. La disminución de la DLCO y del VA con DLCO/VA normal es probablemente determinada por la obstrucción bronquial severa y la mezcla incompleta del gas inspirado en la maniobra de la respiración única de la prueba de difusión

Descriptores: Enfermedad pulmonar obstructiva crónica; Tomografía; Contaminación del aire; Biomasa; Humo; Pruebas de función respiratoria.

\footnotetext{
* Study carried out at the Colombian Pulmonology Foundation, Bogotá, Colombia, and at the Department of Radiology and Diagnostic lmaging, Children's Cardiology Foundation, Cardiology Institute, Bogotá, Colombia.

Correspondence to: Mauricio González-García, Carrera 13B 161-85. Bogotá, Colombia.

Tel. 571 742-8900. Fax. 571 742-8904.E-mail: mgonzalez@neumologica.org

Financial support: None.

Submitted: 17 July 2012. Accepted, after review: 18 December 2012.
} 


\section{Introduction}

Worldwide, approximately three billion people (half of the global population) use either materials of vegetal or animal origin (biomass) or charcoal as a source of energy in the home. ${ }^{(1)}$ In developing countries, the use of wood, dung, crop residues, and charcoal for cooking and heating homes is quite common. Similarly, in developed countries, there has been an increase in the use of wood for heating as an "energy saving" measure. Household air pollution secondary to burning of these materials is a cause of significant morbidity and mortality. ${ }^{(1,2)}$ Chronic household exposure to wood smoke has been associated with the development of chronic bronchitis and COPD and is now accepted as a risk factor for the development of the latter. ${ }^{(3-6)}$

In the mountainous, rural areas of Colombia, the use of wood for cooking is common. Because of the cold, people in those areas usually cook inside their homes in poorly ventilated spaces and on stoves without chimneys, which causes an increase in household air pollution and is a risk factor for the development of COPD, especially in women. The reported prevalence of COPD in Colombia is $8.9 \%$, and, in $6.7 \%$ of the cases, wood smoke exposure was the only COPD risk factor identified. ${ }^{(7)}$ Previous studies have shown that, for a given degree of airway obstruction, the reduction in DLCO is smaller in women with wood smoke-related COPD than in those with smoking-related COPD, and that the DLCO/alveolar volume ratio (DLCO/VA ratio) is normal in the former. ${ }^{(8,9)}$ Although a reduction in DLCO is suggestive of emphysema, this functional behavior has been described in patients with severe obstruction without emphysema and is attributed to involvement of the small airways. ${ }^{(10)}$

The objective of the present study was to describe HRCT findings of emphysema and airway involvement in women with wood smoke-related COPD in terms of severity, and to compare them with those observed in women with smokingrelated COPD.

\section{Methods}

This was a cross-sectional analytical study involving patients with COPD in which two groups were compared (wood smoke-related COPD group vs. smoking-related COPD group). The inclusion criteria were as follows: being female and over 40 years of age; having severe COPD, defined as an $\mathrm{FEV}_{1} / \mathrm{FVC}$ ratio $<70 \%$ and an $\mathrm{FEV}_{1}<50 \%$; and having a history of significant exposure to smoking (smoking history $>20$ pack-years) or to wood smoke (> 20 years). Patients who were exposed to both risk factors were excluded, as were those who experienced exacerbation in the last six weeks and those who had asthma, lung cancer, or tuberculosis sequelae. The study was approved by the local research ethics committee, and all participants gave written informed consent.

The required sample size was calculated to be 8 patients per group, considering a type 1 error of 0.01 and an accuracy of 10\% and using as parameters the values described in a study of subjective assessment of emphysema on HRCT scans in which the mean emphysema score was found to be $9 \pm 7$ in patients with small airways disease and $74 \pm 8$ in patients with COPD. ${ }^{(10)}$ Over an 8 -month period, we selected a non-random sample of consecutive patients enrolled in the COPD program of the institution who attended outpatient follow-up and met the study inclusion criteria. This COPD program has approximately 580 patients, $40 \%$ of whom have severe COPD. The final study simple comprised 22 women with severe COPD, 12 of whom had wood smoke-related COPD and 10 of whom had smoking-related COPD.

Spirometry with bronchodilator testing, determination of single-breath DLCO, and plethysmographic measurement of thoracic gas volume and airway resistance (Vmax 229 AutoBox; Sensormedics Inc., Yorba Linda, CA, USA) were performed in accordance with the criteria of the American Thoracic Society and the European Respiratory Society, and the reference equations of Crapo were used. ${ }^{(11-14)}$

Emphysema was quantified by HRCT of the chest, in accordance with a previously described method, ${ }^{(15,16)}$ with a Somatom AR HP CT scanner (Siemens Medical Systems, Munich, Germany). Six high-resolution slices were performed at $1-\mathrm{mm}$ collimation, in the supine position, during a breath hold: at 3 and $6 \mathrm{~cm}$ above the carina; at the level of the carina; and at 3,6, and $9 \mathrm{~cm}$ below the carina. Images were reconstructed with bone algorithm with a level of $-600 \mathrm{HU}$ and a window width of 1,500 HU. Emphysema severity was classified on a 0-3 scale: $0=$ no emphysema; 1 = areas of low attenuation 
measuring less than $5 \mathrm{~mm}$ in diameter; $2=$ well-circumscribed areas of low attenuation measuring more than $5 \mathrm{~mm}$, in addition to circumscribed areas measuring less than $5 \mathrm{~mm}$; $3=$ diffuse areas of low attenuation (which are not circumscribed) without signs of healthy lung parenchyma or large confluent areas of low attenuation. Emphysema extent was classified on a 1-4 scale on the basis of the degree of involvement on each slice: 1 = below $25 \%$; $2=$ from $26 \%$ to $50 \%$; 3 = from $51 \%$ to $75 \%$; and $4=$ above $76 \%$. Each slice was assessed individually, and the right and left lungs were quantified separately. For each of the 12 slices, the severity score was multiplied by the extent score, and, subsequently, summation was performed to calculate the final emphysema score, the maximum possible score being 144 points. A score between 0 and 50 was classified as mild emphysema, a score between 51 and 100 was classified as moderate emphysema, and a score above 101 was classified as severe emphysema.

In order to assess peripheral airway involvement, 5 slices were performed at end-expiration as described previously ${ }^{(17,18)}$ : at the level of the aortic arch; at the level of the carina; $y$ at 3, 6, and 9 $\mathrm{cm}$ below the carina. The following criteria were used-mosaic pattern: areas of normal-looking lung parenchyma on slices obtained during inhalation that show decreased attenuation coefficient and a decreased artery-to-bronchus ratio on slices obtained during exhalation; peribronchial thickening: linear or branching opacity in the center of the lobule when the bronchiole is parallel to the slice plane; tree-in-bud pattern: obliteration of the terminal bronchioles, which are seen as centrilobular nodules; and cylindrical bronchial dilation (bronchiectasis).

The images were interpreted independently by two radiologists and one pulmonologist, experts in HRCT of the chest, who were blinded to the clinical diagnosis. Subsequently, the images were read jointly by the three observers, also in a blinded fashion, in order to achieve consensus. Interobserver variability was assessed, as was agreement between the individual readings and the consensus reading.

Qualitative variables are expressed as proportions, whereas quantitative variables are expressed as means and standard deviations or as medians and interquartile ranges. Chi-square statistics were used for categorical variables, whereas the Student's t-test or the nonparametric Mann-Whitney U test was used for continuous variables. We estimated Lin's concordance correlation coefficient and Bland \& Altman limits of agreement between the HRCT scores obtained in the individual readings and those obtained in the consensus reading. All tests were two-tailed, and the level of significance was set at $p<0.05$. We used the STATA statistical program, version 7.0 (Stata Corp., College Station, TX, USA).

\section{Results}

The patients with wood smoke-related COPD had a history of $41.2 \pm 9.8$ years of exposure to wood smoke, whereas those with smokingrelated COPD had a smoking history of 47.0 \pm 16.2 pack-years. There were no significant differences between the two groups in terms of age or body mass index (Table 1).

All patients had severe obstruction, as well as a significant increase in total lung capacity, functional residual capacity, and airway resistance. There were no significant differences between the two groups in terms of the degree of impairment. In the women with wood smoke-related COPD, the DLCO and DLCO/VA ratio were significantly higher, whereas the VA was lower, than in the women with smoking-related COPD (Table 1).

The emphysema scores, expressed as median (interquartile range), were significantly lower in the wood smoke-related COPD group than in the smoking-related COPD group-0 (0-1) vs. 92.5 (73-103); $p<0.001$; Figure $1-$ and the airway involvement was greater in the former: peribronchial thickening (75\% vs. 10\%; $p=0.008)$ and bronchial dilation ( $67 \%$ vs. $10 \% ; p=0.024$ ). In addition, tree-in-bud and subsegmental atelectasis were observed in women with wood smoke-related COPD (in 25\% and 33\%, respectively), as was severe wall thickening in large bronchi, none of which were found in those with smokingrelated COPD (Figure 2). No mosaic pattern was observed on the slices obtained during exhalation in any patient. The agreement between the initial readings and the consensus readings for emphysema assessment was very good, with a concordance correlation coefficient of 0.937 ( $p<0.001$ ), a mean difference of $0.030 \pm 15.7$ between the scores obtained by the two methods of assessment, and Bland \&t Altman limits of agreement of -30.77 and 30.83 . 
Table 1 - Patient characteristics and pulmonary function test results. ${ }^{\text {a }}$

\begin{tabular}{|c|c|c|c|}
\hline \multirow{3}{*}{ Variable } & \multicolumn{2}{|c|}{ Groups } & \multirow{3}{*}{$\mathrm{p}$} \\
\hline & $\begin{array}{c}\text { Wood smoke-related } \\
\text { COPD }\end{array}$ & Smoking-related COPD & \\
\hline & $(n=12)$ & $(n=10)$ & \\
\hline Age, years & $72.6 \pm 8.7$ & $65.9 \pm 7.3$ & 0.07 \\
\hline $\mathrm{BMl}, \mathrm{kg} / \mathrm{m}^{2}$ & $23.9 \pm 4.6$ & $22.5 \pm 3.7$ & 0.44 \\
\hline FVC, \% of predicted & $62.8 \pm 12.7$ & $65.9 \pm 25.1$ & 0.72 \\
\hline $\mathrm{FEV}_{1}, \%$ of predicted & $36.0 \pm 11.0$ & $32.4 \pm 17.7$ & 0.57 \\
\hline $\mathrm{FEV}_{1} / \mathrm{FVC}, \%$ & $44.3 \pm 9.4$ & $37.6 \pm 7.2$ & 0.08 \\
\hline TLC, \% of predicted & $131.5 \pm 29.1$ & $137.5 \pm 15.5$ & 0.55 \\
\hline FRC, \% of predicted & $189.7 \pm 61.9$ & $196.0 \pm 26.0$ & 0.75 \\
\hline RV, \% of predicted & $211.3 \pm 74.0$ & $226.5 \pm 47.6$ & 0.58 \\
\hline RV/TLC, $\%$ & $70.4 \pm 9.3$ & $70.1 \pm 10.0$ & 0.94 \\
\hline sRaw, \% of predicted & $1,125.3 \pm 621.0$ & $1,227.4 \pm 569.8$ & 0.69 \\
\hline sGaw, $\%$ of predicted & $10.8 \pm 5.6$ & $10.8 \pm 6.8$ & 0.99 \\
\hline DLCO, \% of predicted & $57.9 \pm 14.2$ & $35.1 \pm 10.7$ & $<0.001$ \\
\hline DLCO/VA, \% of predicted & $94.4 \pm 19.9$ & $41.8 \pm 11.6$ & $<0.001$ \\
\hline VA, $\%$ of predicted & $60.0 \pm 13.3$ & $85.8 \pm 17.8$ & 0.001 \\
\hline
\end{tabular}

BMI: body mass index; FRC: functional residual capacity; VA: alveolar volume; sRaw: specific airway resistance; and sGaw: specific airway conductance. ${ }^{a}$ Values expressed as mean \pm SD.

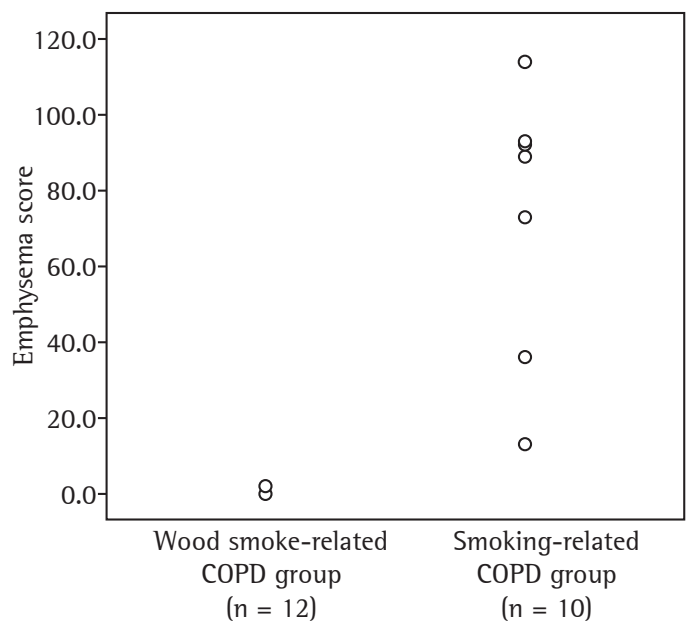

Figure 1 - Emphysema scores (as determined by HRCT) in the wood smoke-related COPD group and in the smoking-related COPD group. The emphysema scores [median (interquartile range)] were significantly higher in women with smoking-related COPD than in women with wood smoke-related COPD [92.5 (73-103) vs. 0 $(0-1) ; p<0.001]$.

\section{Discussion}

In this study based on chest HRCT findings, we demonstrated that, unlike women with smoking-related COPD, those with wood smokerelated COPD and severe obstruction do not have emphysema, although they have significant airway involvement manifesting as peribronchial thickening, bronchial dilation, and subsegmental atelectasis. These findings correlated with the fact that the change in DLCO and in the DLCO/ VA ratio, as determined by pulmonary function tests, was smaller in women with wood smokerelated COPD than in those with smoking-related COPD, a finding that has been described in cases of severe small airways involvement and little emphysema. ${ }^{(10)}$

Functionally, all patients showed lung volume hyperinflation with a marked increase in functional residual capacity and residual volume, as well as a significant increase in airway resistance as measured by plethysmography, there being no differences between the two groups. Despite the same degree of obstruction, the reduction in DLCO and in the DLCO/VA ratio was significantly smaller in the wood smoke-related COPD group than in the smoking-related COPD group.

The tomographic findings confirmed the absence of significant emphysema in women with wood smoke-related COPD and showed moderate emphysema in women with smoking-related COPD. Previous studies have demonstrated that this subjective quantification of emphysema on HRCT scans correlates significantly with pathologic grading of emphysema on the basis of microscopic 

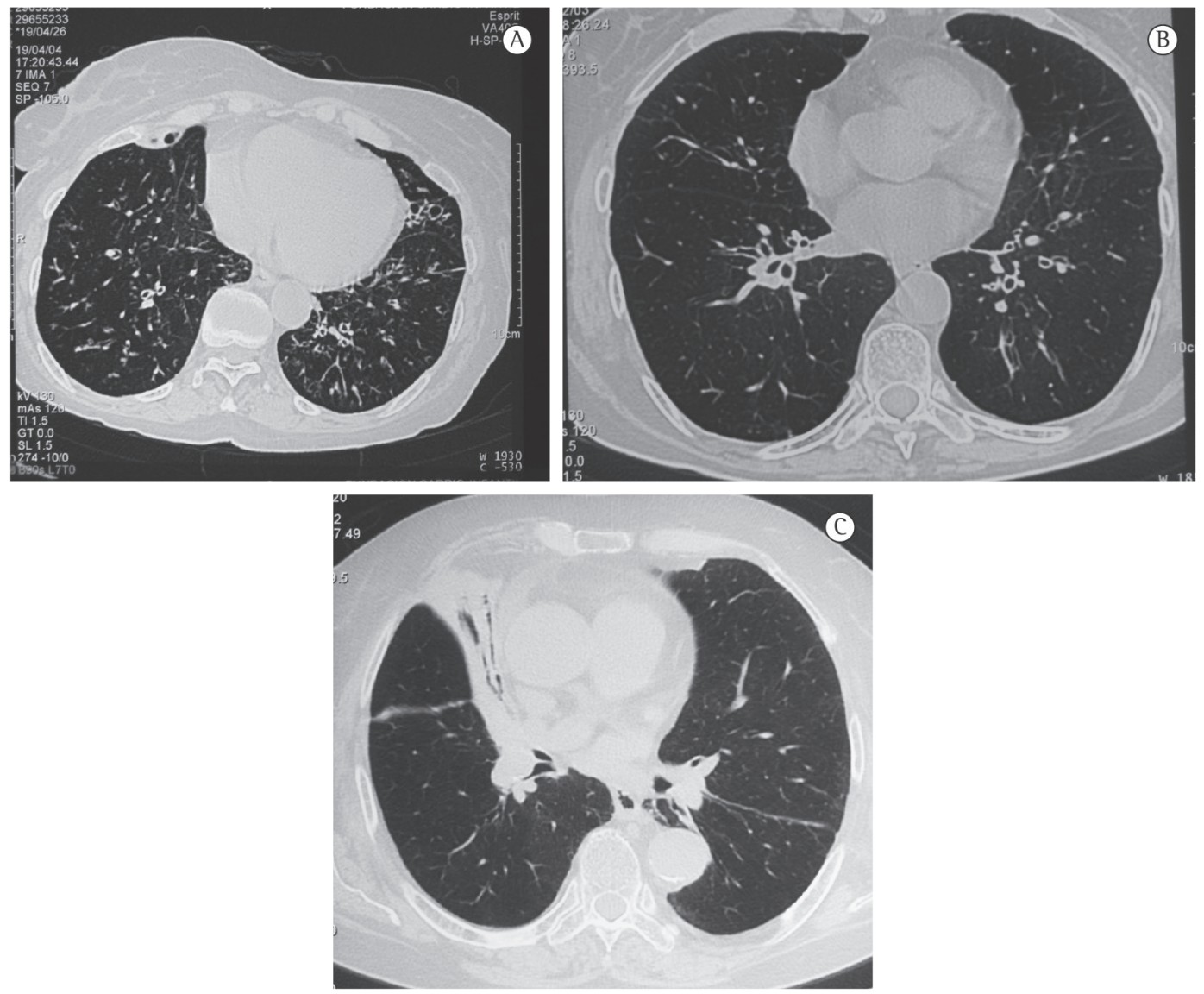

Figure 2 - HRCT scans showing airway involvement in patients with wood smoke-related COPD. In A, bronchial thickening and bronchiectasis; in B, bronchial dilation; and in $\mathrm{C}$, middle lobe atelectasis.

examination of resected lung specimens. ${ }^{(19,20)}$ Although this subjective quantification might have disadvantages, such as overestimation of the degree of emphysema and, sometimes, low agreement among different observers, ${ }^{(21)}$ we believe that the technique used in our study was adequate, considering the clear differences found between the two groups and the good agreement observed between the individual readings by the three observers and the consensus readings. Therefore, our results are highly reproducible. As indicated earlier in this article, women exposed to wood smoke, in addition to not having emphysema, were found to have peribronchial thickening, bronchiolar and bronchial dilation, and subsegmental atelectasis, which are evidence of significant airway involvement. The presence of atelectasis is a common finding in individuals with wood smoke-related COPD and has been correlated with endoscopic and histological findings of anthracosis and bronchial inflammation..$^{(9,2)}$
Although other studies have not found that the frequency of cough and sputum production is higher in women with wood smoke-related COPD than in those with smoking-related COPD, ${ }^{(23,24)}$ probably because of differences in the degree of exposure or disease severity, previous studies conducted in Colombia have found that women exposed to wood smoke have a higher frequency of cough and expectoration, as well as increased bronchial hyperresponsiveness, which suggests greater airway involvement, a finding that is similar to that of the present study. ${ }^{(9,25)}$ A study involving 86 patients with wood smoke-related COPD and 53 patients with smoking-related COPD, with different degrees of obstruction, found that the reduction in DLCO was less severe and was less correlated with the degree of obstruction (reduction in $\mathrm{FEV}_{1}$ ) in the former than in the latter, and that the DLCO/VA ratio was normal in the former, ${ }^{(9)}$ findings that are similar to those of the present study. This functional behavior, 
i.e., the reduction in DLCO with a normal DLCO/ VA ratio, suggests that there is greater airway involvement and less emphysema, as has been reported in patients with severe obstruction without emphysema, in whom expiratory flow limitation has been attributed to small airways involvement rather than to an emphysemarelated reduction in elastic recoil alone. ${ }^{(10,26,27)}$ Because there were no tomographic findings of emphysema, those authors attributed the reduction in DLCO to a reduction in VA or a spurious reduction in DLCO, and introduced the term pseudophysiologic emphysema, which can be applied to female patients with wood smoke-related COPD.

The major determinants of DLCO are the rate of alveolar-capillary gas exchange (permeability factor) and VA, which determines the quantity of gas available for exchange. In individuals with obstructive lung disease, VA measured during the determination of single-breath DLCO is low because of incomplete mixing of inspired gas and residual lung gas during breath holding, which can lead to a reduction in DLCO. In individuals with emphysema, the reduction in alveolar-capillary surface area leads to a proportionally greater reduction in DLCO than does the reduction in VA, which causes a significant reduction in the DLCO/VA ratio. ${ }^{(28,29)}$ We believe that, in women with wood smoke-related COPD, in whom we found little emphysema, maldistribution of inspired gas during the determination of single-breath DLCO, because of the airway disease, can explain the reduction in VA and DLCO and the lesser change in the DLCO/VA ratio, which was normal in some cases.

Airflow limitation in individuals with COPD is attributed to lung parenchymal destruction and reduced elastic recoil, as well as to inflammation and obliteration of the airways. Although we did not measure elastic recoil, we postulate, on the basis of the findings of this study, that the reduced airflow in female patients with severe wood smoke-related COPD is explained mainly by severe airway impairment rather than by loss of elastic recoil due to emphysema. These functional and tomographic findings of no or minimal emphysema correlate with the findings a retrospective study of 103 autopsies of patients exposed to wood smoke. Although clinical and pulmonary function data from those patients were not recorded, the major histological findings in that group were hypertensive pulmonary vascular disease; peribronchial, perivascular, and interstitial deposition of anthracotic pigment; and no emphysema. ${ }^{(30)}$

One of the limitations of this study was the inclusion of a relatively small number of patients. However, the selection of consecutive cases, the strict inclusion criteria on the basis of the type of exposure (wood smoke or smoking), and the exclusion of those who were simultaneously exposed to both factors led to the formation of two groups that are clearly comparable. On the basis of the selection criteria, we included only women with severe obstruction, which is why the results obtained cannot be generalized to other degrees of severity or to men with COPD. Further studies involving a large number of patients with different degrees of obstruction are needed in order to confirm the findings of the present study.

In conclusion, in female patients with severe wood smoke-related COPD, HRCT scans showed no significant emphysema, the main finding being severe airway involvement manifesting as peribronchial thickening, bronchial dilation, and subsegmental atelectasis. The reduction in DLCO and VA, with a normal DLCO/VA ratio, is due to severe bronchial obstruction and maldistribution of inspired gas during the determination of single-breath DLCO. We believe that the airflow obstruction in these patients is mainly caused by severe airway involvement rather than by a loss of elastic recoil due to emphysema, a finding that contributes to the understanding of COPD and indicates that pathophysiologically distinct diseases with one shared clinical manifestation (airflow obstruction), which might depend on the type of irritant or contaminant, are being included under the designation of COPD.

\section{References}

1. Torres-Duque C, Maldonado D, Pérez-Padilla R, Ezzati M, Viegi G; Forum of International Respiratory Studies (FIRS) Task Force on Health Effects of Biomass Exposure. Biomass fuels and respiratory diseases: a review of the evidence. Proc Am Thorac Soc. 2008;5(5):577-90.

2. Arbex MA, Cançado JE, Pereira LA, Braga AL, Saldiva PH. Biomass Burning and Health Effects. J Bras Pneumol. 2004;30(2):158-75.

3. Dennis RJ, Maldonado D, Norman S, Baena E, Martinez G. Woodsmoke exposure and risk for obstructive airways disease among women. Chest. 1996;109(1):115-9.

4. Hu G, Zhou Y, Tian J, Yao W, Li J, Li B, et al. Risk of COPD from exposure to biomass smoke: a metaanalysis. Chest. 2010;138(1):20-31. 
5. Rabe KF, Hurd S, Anzueto A, Barnes PJ, Buist SA, Calverley $P$, et al. Global strategy for the diagnosis, management, and prevention of chronic obstructive pulmonary disease: GOLD executive summary. Am J Respir Crit Care Med. 2007;176(6):532-55.

6. da Silva LF, Saldiva SR, Saldiva PH, Dolhnikoff M; Bandeira Científica Project. Impaired lung function in individuals chronically exposed to biomass combustion. Environ Res. 2012;112:111-7.

7. Caballero A, Torres-Duque CA, Jaramillo C, Bolívar F, Sanabria F, Osorio P, et al. Prevalence of COPD in five Colombian cities situated at low, medium, and high altitude (PREPOCOL study). Chest. 2008;133(2):343-9.

8. González-García M, Barrero M, Maldonado D. Carbon monoxide diffusing capacity (DLCOSB) and transfer coefficient (DLCO/VA) in wood smoke chronic obstructive pulmonary disease (COPD) in Bogota, Colombia (2640 m). Chest. 2001;120:289S.

9. González M, Páez S, Jaramillo C, Barrero M, Maldonado D. Enfermedad pulmonar obstructiva crónica (EPOC) por humo de leña en mujeres: comparación con la EPOC por cigarrillo. Acta Med Colomb. 2004;29(1):17-25.

10. Gelb AF, Zamel N, Hogg JC, Müller NL, Schein MJ. Pseudophysiologic emphysema resulting from severe small-airways disease. Am J Respir Crit Care Med. 1998;158(3):815-9.

11. Crapo RO, Morris AH, Gardner RM. Reference spirometric values using techniques and equipment that meet ATS recommendations. Am Rev Respir Dis. 1981;123(6):659-64.

12. Macintyre N, Crapo RO, Viegi G, Johnson DC, van der Grinten CP, Brusasco V, et al. Standardisation of the single-breath determination of carbon monoxide uptake in the lung. Eur Respir J. 2005;26(4):720-35.

13. Miller MR, Hankinson J, Brusasco V, Burgos F, Casaburi $\mathrm{R}$, Coates A, et al. Standardisation of spirometry. Eur Respir J. 2005;26(2):319-38.

14. Wanger J, Clausen JL, Coates A, Pedersen OF, Brusasco V, Burgos F, et al. Standardisation of the measurement of lung volumes. Eur Respir J. 2005;26(3):511-22.

15. Hunsaker A, Ingenito E, Topal U, Pugatch R, Reilly J. Preoperative screening for lung volume reduction surgery: usefulness of combining thin-section CT with physiologic assessment. AJR Am J Roentgenol. 1998;170(2):309-14.

16. Klein JS, Gamsu G, Webb WR, Golden JA, Müller NL. Highresolution CT diagnosis of emphysema in symptomatic patients with normal chest radiographs and isolated low diffusing capacity. Radiology. 1992;182(3):817-21.

17. Müller NL, Miller RR. Diseases of the bronchioles: CT and histopathologic findings. Radiology. 1995;196(1):3-12.
18. Stern EJ, Frank MS. Small-airway diseases of the lungs: findings at expiratory CT. AJR Am J Roentgenol. 1994;163(1):37-41.

19. Bergin C, Müller N, Nichols DM, Lillington G, Hogg JC, Mullen B, et al. The diagnosis of emphysema. A computed tomographic-pathologic correlation. Am Rev Respir Dis. 1986;133(4):541-6.

20. Kuwano K, Matsuba K, lkeda T, Murakami J, Araki A, Nishitani $\mathrm{H}$, et al. The diagnosis of mild emphysema. Correlation of computed tomography and pathology scores. Am Rev Respir Dis. 1990;141(1):169-78.

21. Bankier AA, De Maertelaer V, Keyzer C, Gevenois PA. Pulmonary emphysema: subjective visual grading versus objective quantification with macroscopic morphometry and thin-section CT densitometry. Radiology. 1999;211(3):851-8.

22. Restrepo J, Reyes P, de Ochoa P, Patiño E. Neumoconiosis por inhalación de humo de leña. Acta Med Colomb. 1983;8(4):191-204.

23. Moreira MA, Moraes MR, Silva DG, Pinheiro TF, Vasconcelos Júnior HM, Maia LF, et al. Comparative study of respiratory symptoms and lung function alterations in patients with chronic obstructive pulmonary disease related to the exposure to wood and tobacco smoke. J Bras Pneumol. 2008;34(9):667-74.

24. Ramírez-Venegas A, Sansores RH, Pérez-Padilla R, Regalado J, Velázquez A, Sánchez C, et al. Survival of patients with chronic obstructive pulmonary disease due to biomass smoke and tobacco. Am J Respir Crit Care Med. 2006;173(4):393-7.

25. González-García M, Torres-Duque CA, Bustos A, Jaramillo C, Maldonado D. Bronchial hyperresponsiveness in women with chronic obstructive pulmonary disease related to wood smoke. Int J Chron Obstruct Pulmon Dis. 2012;7:367-73.

26. Gelb AF, Schein M, Kuei J, Tashkin DP, Müller NL, Hogg JC, et al. Limited contribution of emphysema in advanced chronic obstructive pulmonary disease. Am Rev Respir Dis. 1993;147(5):1157-61.

27. Gelb AF, Hogg JC, Müller NL, Schein MJ, Kuei J, Tashkin DP, et al. Contribution of emphysema and small airways in COPD. Chest. 1996;109(2):353-9.

28. Fitting JW. Transfer factor for carbon monoxide: a glance behind the scene. Swiss Med Wkly. 2004;134(29-30):413-8.

29. Hughes JM, Pride NB. In defence of the carbon monoxide transfer coefficient Kco (TL/VA). Eur Respir J. 2001;17(2):168-74.

30. Palacios D, Mendez O. Neumopatía por humo de leña: un estudio en autopsias. Biomédica (Bogota). 1998;18(2):153-60. 


\section{About the authors}

\section{Mauricio González-García}

Internist, Pulmonologist, and Clinical Epidemiologist. Research Department, Colombian Pulmonology Foundation, Bogotá, Colombia.

\section{Dario Maldonado Gomez}

Internist, Pulmonologist, and Director. Colombian Pulmonology Foundation, Bogotá, Colombia.

\section{Carlos A. Torres-Duque}

Internist and Pulmonologist. Research Department, Colombian Pulmonology Foundation, Bogotá, Colombia.

\section{Margarita Barrero}

Physical Therapist. Pulmonary Function Laboratory, Colombian Pulmonology Foundation, Bogotá, Colombia.

\section{Claudia Jaramillo Villegas}

Internist and Cardiologist. Research Department, Colombian Pulmonology Foundation, Bogotá, Colombia.

\section{Juan Manuel Pérez}

Radiologist. Department of Radiology and Diagnostic Imaging, Children's Cardiology Foundation, Institute of Cardiology, Bogotá, Colombia.

\section{Humberto Varon}

Radiologist. Department of Radiology and Diagnostic Imaging, Children's Cardiology Foundation, Institute of Cardiology, Bogotá, Colombia. 